\title{
From Colonial Coroner to American Medical Examiner: A Way Forward in Sri Lankan Death Investigation System
}

\author{
Samadhi DAH ${ }^{1 *}$, Ruwanpura PR ${ }^{1}$, Amararatne RRGS $^{2}$ \\ ${ }^{1}$ Office of the Judicial Medical Officer, Teaching Hospital Karapitiya, Sri Lanka, ${ }^{2}$ Office of the Judicial Medical \\ Officer, District General Hospital, Kalutara, Sri Lanka.
}

\begin{abstract}
The Death Investigation system (DIS) in a given country is an administrative office, that is essential in many directions. Different DIS are existing worldwide differing on its investigating authority but are mainly consisted of Coroner and Medical Examiner systems. These systems are indefinitely being modified to be fitted with the advancement of forensic investigations and social needs, and the trend runs towards the medically trained Death Investigator System. Current DIS in Sri Lanka is adopted from the British Coronial system and is still being practised without significant adjustments since 1892, which has given rise to numerous discrepancies. The objective is to emphasizes the need for establishing the Medical Examiners (ME) System in Sri Lanka and to address the issues in converting to the proposed system. The Main drawbacks concerning this conversion in other countries are related to administrative, legislative, financial, and political issues. Nevertheless, every country does not acquire similar challenges, and our country may easily accept and overcome the difficulties mentioned above. As an example, the current DIS can be swiftly converted into ME centered approach with minor modifications to the criminal procedure code such as by appointing a Forensic Medical specialist as a death investigator with all the powers of existing Inquirer into Sudden Death who can conduct inquest to decide whether autopsy examination is necessary or not. This process does not require any infrastructural modifications as well. Stepwise conversion of Coroners to ME in the States in America can be taken into consideration as a role model. This paper highlights the necessity of introducing the Medical Examiner System in Sri Lanka and provides guidance to overcome the drawbacks.
\end{abstract}

Keywords: Coroner, Death Investigation, ISD, Medical Examiner

Received: 29 Nov 2020, Revised version accepted: 29 Dec 2020, Published: 31 Dec 2020. *Corresponding author: Samadhi DAH, $\triangle$ Email: dahsamadhid@gmail.com, (D) https://orcid.org/0000-0003-4814-6255

Cite this article as: Samadhi DAH, Ruwanpura PR, Amararatne RRGS. From Colonial Coroner to American Medical Examiner: A Way Forward in Sri Lankan Death Investigation System. Medico-Legal Journal of Sri Lanka, 2020;8(2):40-44. DOI: http://dx.doi.org/10.4038/mljsl.v8i2.7425

Copyright: @ 2019 with the Medico-legal Journal of Sri Lanka.

This is an open-access article distributed under the terms of the Creative Commons Attribution 4.0 International License, which permits unrestricted use, distribution, and reproduction in any medium provided the original author and source are credited.

\section{Introduction}

Examination, correlation, and interpretation of deaths are carried out under different legislations in different states which is critical for criminal justice; as well as to aid in civil litigations. ${ }^{[1]}$ Contribution of it in public health, especially in research, mortality analysis, and assessment of medical care, surveillance, prevention and control, personal liberty and freedom, financial well -being are equally important. One of the main challenges faced by the legal system is to facilitate a credible and objective process to investigate a death, thence the justice with convicting the guilty and protecting the innocent. ${ }^{[2]}$

\section{- History of death investigation systems (DIS)}

Origin of Forensic science has a long history way back to thousand years and documented in China in an early transcript of the text, Washing Away of Wrongs by Sung Tz'u written in 1248AD. ${ }^{[3]}$ The first recorded case of a death investigation by a medical expert refers to the assassination of Julius Caesar in 44 BC where an Ancient Roman Physician Antistius examined the dead body and concluded that out of twenty-three stabs, only one penetrating injury between left third and fourth ribs was fatal. ${ }^{[4]}$ Hence, Antistius is virtually a first-ever recognized medical examiner in history.

The first case of Magistrate ordered postmortem examination was conducted in Bologna, Italy in $1302 \mathrm{AD}$ by the panel of three Physicians, ${ }^{[5]}$ on a body of a young man who died in questionable circumstances. In ancient Ceylon, during the Kandyan Kingdom, 1593-1815AD, there had been an independent death investigation tribunal named "Sakshi Balanda" [evidence into], which inquired into a manner of suspicious deaths ${ }^{[6]}$, but there is no evidence about Physician's involvement in death investigations. ${ }^{[7]}$ The British coronial system was implemented through $1883 \mathrm{AD}$ as a modified model 
of the English coroners' system. ${ }^{[8]}$ In 1958 AD the United States passed the model postmortem act which outlines the general classes of deaths that need to be investigated and was the framework to develop its own laws regarding death investigation to their states. Over the years these systems are indefinitely being modified to be fitted with the advancement of forensic investigations and social needs.

\section{- Overview for Current Main DIS in the world}

There has been a number of systems of death investigations adopted in different geographical regions of the world, primarily differ by the office of the investigating authority. However, irrespective of the legal authority of the investigation, autopsies are exclusively conducted by Forensic pathologists.

- Police investigations -In India, the Caribbean Islands, and the Middle east the death investigations are accomplished by the form of the inquest which are carried out by the Police or and referred to the Coroner or Magistrate depending on the circumstances. ${ }^{[9]}$

- Procurator fiscal ${ }^{[10]}$ or District attorney in Continental Europe, Russian Federation ${ }^{[1]}$ and Scotland. Scotland is separated from England by its legal systems, and certain types of deaths are investigated as fatal accident inquiries [FAI] by a Procurator Fiscal who has the ability to impose a fiscal fine as well.

- Investigating concurrently by the Prosecutor General and the state pathologist in the Scandinavian system. $^{[12]}$

- Medical examiner system - Medical examiners are trained Physicians, Pathologists, or Forensic Pathologists with jurisdiction over a country district or state who can initiate inquest and investigate a death or to conduct postmortem examination in some instances. ${ }^{[13]}$

- Coronial investigation system - The office of the Coroner originated in Medieval England and has also been proceeded in countries subjected to the British empire Australia, Canada, and in some states in America.[14] Sri Lanka has inherited the Coroners system in the early nineteenth century, but unlike in England and Wales, the system did not change significantly during the last hundred years.

- DIS in Sr Lanka... "Coroners act in 1882"

English Death Investigation System is adopted in Sri Lanka according to the provision of the Code of Criminal Procedure Act (No 15 of 1979)-Sect 367373. ${ }^{[15]}$ Nevertheless, there are some differences in our system to what currently existing in England. It has to be emphasized that inquest conducted under the above legal provisions are different from legal or administrative inquiries. The inquest is essentially a fact-finding exercise to reveal the cause and circumstantial background of a particular death and shall not be confused with an inquiry against the accused/responsible persons. Therefore, an inquirer into sudden death [ISD] is empowered to call upon any person, including treating Physicians, documentation or any other relevant material. ${ }^{[16]}$

Every inquire on receiving information's (through the Police, Citizens or Medical Officer in a case of hospital death) that a person

(a) has committed suicide

(b) has been killed by an animal, machinery or by accident or

(c) has died suddenly or from a cause of which is not known. Shall hold an inquest and the duly signed inquest report by such an inquires shall be forthwith forwarded to the nearest Magistrate. If the notice or other material before him discloses a reasonable suspicion that a crime has been committed the Magistrate shall take a proceeding under Chapter xiv and $\mathrm{XV}$ and in such event, the record of the inquiry and the inquirer's report shall be annexed to the record of proceedings before the Magistrate. The inquest procedures are coordinated by the Police. Under special provisions of national security enactments, an order for autopsy may be issued by the High Court. ${ }^{[17]}$

Significant advantages of the current coronial investigation system in Sri Lanka are autonomy, access to power, and the ability to represent the will of the electorate though, and this system is currently out weighted by its disadvantages.

\section{Objectives and Discussion}

\section{- Why is it need to be changed...?}

Medico-legal death investigation; is a process in which there is an interconnection between few components as below. If any element is lacking the investigation seems incomplete.

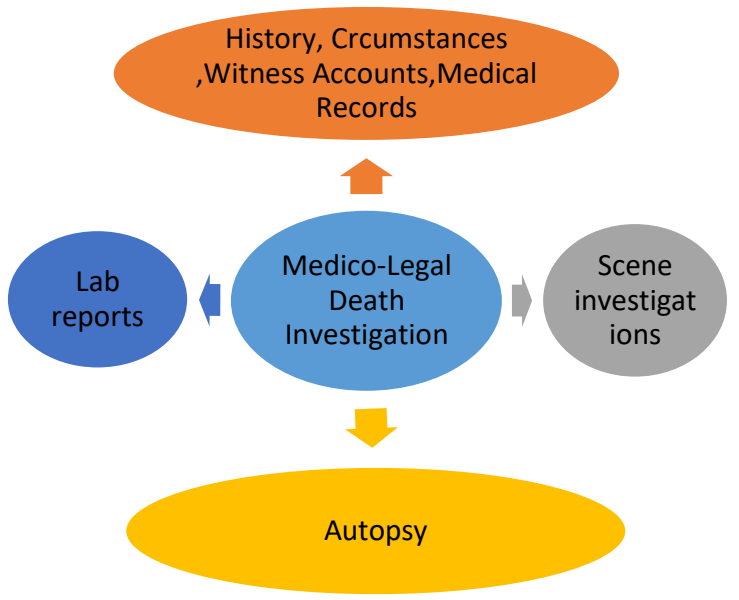


Most of the parts of the death investigation process are medically oriented which needs the assistance of a medical professional, apart from that some investigations are more complex and necessarily need specially trained Physicians. When a Coroner/ISD gives his opinion to a medico-legal finding, it may not correctly refer, as a "medical opinion". This discrepancy has led to the unrelated and unpopular determination of cause and the manner of death for years in Sri Lanka.

"A study done in 1995 in Faculty of Medicine, University of Colombo to analyse the causes and circumstances of deaths reported for an inquest, found that 868 cases reported to the inquirer, the circumstances were not determined in 94 cases at the initial inquest proceedings "[18]

There are enough incidents in Sri Lankan literature, where the inquires interpret the injuries and formulate their opinion beyond their limitation; which contradicted the view of Forensic pathologist. ${ }^{[19]}$ There the inquirer has reported the post -mortem artefacts due to ant bites as the injuries caused by a rifle butt. ${ }^{[20]}$

Medical examiners are almost always Physicians, usually Pathologists and occasionally Forensic pathologists. But in some states in America, a Physician, not necessarily a Pathologist, who assists in death investigation or functions like a coroner, and in some states of America; ideally, a medical examiner must be a Forensic pathologist, assuring the certification of death may be more reliable and accurate and will positively modify the quality of death investigation system. ${ }^{[21]}$

ISD/Coroners, mostly being laypersons have no ability and power to take any decisions and recommendations regarding public health and hazards, and there is no proper communication with the epidemiological database in relation to mortality statistics and health care deliveries.

Apart from that, the Coroners/ISD are appointed by the Secretary of justice, ${ }^{[2]}$ but often politically nominated and have their political ties which interfere with the independence of the procedures of investigations. That places the Coroner/ISD in a higher position who has an unnecessary power to summon the professionally qualified Pathologists, Physicians. There were such reported unpleasant experiences between those two parties in the recent past and which ended with long-term conflicts in between them, ultimately affects a proper investigation. ${ }^{[19]}$ On the other hand, there may be conflicts of interest towards some parties like funeral directors, prosecutors, etc.
Over the years, there has been a trend of converting the coronal death investigation system to appoint medical examination system worldwide. ${ }^{[23]}$ Statewide distribution of the Medical examiner system in the USA being the best example highlights its advantages related to the quality of death investigation, uniformity, and central administration. After the 1990s there is a considerable degree of decline in this conversion which is justified with issues on administrative and legislative matters, geographical, financial issues etc. ${ }^{[21]}$

\begin{abstract}
- How far is it applicable to Sri Lanka? And how to overcome the difficulties of the introduction and establishment of the new system?

The introduction of a new system of death investigation to Sri Lanka is quite arguable. The establishment of it is not a one-day target, hence the stepwise approach is needed. It is wise to consider the common challenges and the resolutions of the countries which adopted the medical examiner system were faced.
\end{abstract}

\section{-Administrative and legislative issues/statuary /constitutional issues}

The present fleet of Forensic medical experts in Sri Lanka, through their postgraduate training and experience, do possess sufficient skills and knowledge to conduct death investigations according to the requirement of the law, undoubtfully better than an Inquirer into Sudden Death (ISD)/Coroner. The current death investigation system can be swiftly converted into medical examiner centred system with minor modifications to the criminal procedure code. There needs to be a provision to appoint a Forensic medical specialist as a death investigator with all the powers of existing ISD/Coroner, and the medical examiner can conduct an inquest to decide whether autopsy examination is necessary or not and Medical examiner need to be made accountable to the Magistrate regarding the outcome of the inquest and autopsy. Indeed, being designated a medical examiner poses an additional legal responsibility on the Forensic pathologist.

Medical examiners or trained death scene investigator ${ }^{[24]}$ can visit the scene of death/houses and can also replace the duty of "Grama Niladhari"a village officer / ISD in the certification of death and finalize the cause and manner of death in a more scientific context avoiding unnecessary delays and time-consuming costly investigations. Even one medical officer can cover an entire administrative district in this a provided that adequate transport facilities are arranged. Such initiations can subsequently be expanded into a widespread service system which may cover the whole country. 


\section{- Financial issues}

This process does not require any infrastructural modifications; the existing facilities of the forensic units of the health institutions and human resources can be utilized for this purpose with no additional financial burden to the government. In fact, the medical examiner can use the current facilities under his inventory in a more efficient manner. Presumptive estimations suggest that the medical examiners can operate more economically than the coroners as they share the same duties with adequate compensation.

\section{-Political/elective issues}

There may be political issues in changing the death investigation system, especially when coroners are replaced since Coroners are historically an integral part of government and politics which partially explains their continued existence. The current coroner appointments are made on three -year contracts and these political issues could be eased through step by step transformation. It is indeed incredible to think that just the space of a few yards may mean the difference between competent death investigation and incompetent death investigation.

\section{- Geographical and population-based issues}

At present, there is an adequate number of Forensic pathologists are stationed in all the major centers in line with the population density of different regions of the country. According to current training statistics, within the next ten years, the estimated number of Board-certified Forensic pathologists may exceed 100, and all parts of the country will be comprehensively covered by the services of the specialized Forensic medical expertise. Of course, it is necessary to launch a public awareness campaign to enhance the awareness of the general masses about the advantages of the medical examiner system over the Coroner's inquest.

During the initial stage of introduction of the new system, it is more appropriate to establish the medical examiners first in the teaching hospital centers as done in America and then gradually decentralize the system. It may also lead to eliminating the desired local contacts provided by the Coroners. Anyway, whether it is centralized or decentralized Medical examiner system has many advantages over the Coroner's system or mixed system.

\section{-Human resources availability and distribution}

There may be a need for trained clerical and technical assistants to help medical experts in investigating procedure. The supporting staff who are already attached to the medico-legal units are thorough with the necessary medico-legal procedures, especially concerning death investigations. The same workforce can be used to proceed with the new system with some advanced professional training.

\section{- Lack of interest}

Educate the population and the law enforcement authorities regarding the outcome, and the beneficiaries of the medical examiner system are essential to be successful in overcoming the lack of local interest in changing the procedures.

\section{- Market saturation}

Conversion to the new investigating system needs more intensified effort with changing laws, continuous funding, and staff.

\section{Conclusions}

However, there is room for more standardized practice in medico-legal death investigation to assure a high-quality systematic approach in order to overcome the shortcomings of the present systems. Every country does not acquire similar challenges in the process of modification or conversion to a different system. Nevertheless, there are enough evidence of the advantages being converting to the Medical Examiner System.

"Systems do not change easily. Systems try to maintain themselves and seek equilibrium. To change a system, you need to shake it up, disrupt the equilibrium that often requires conflicts."

\section{Disclosure statement}

Conflicts of interest: The authors declare that they have no conflicts of interest.

\section{Funding: None}

\section{References}

1. Hanzlick R. Death investigation: systems and procedures. CRC Press; 2017 Aug 21.

2. Carpenter B, Tait G, Quadrelli C, Thompson I. Investigating death: The emotional and cultural challenges for police. Policing and Society. 2016 Aug 17;26(6):698-712.

3. Song C. The washing away of wrongs: forensic medicine in thirteenth-century China. University of Michigan Press; 1981.

4. Chao TC. Forensic Medicine: The Changing Roles for the Challenges Ahead. Malaysian Journal of Pathology. 1991;13(1):1-4.

5. Rodrigues EJ, Kantak MP. Panel autopsy. Journal of South Journal of South India Medicolegal India Medicolegal Association Association. 2010 Mar;2(1):17-21.

6. Wijebandara C. A Critical Analysis of the Present Death Investigation System in Sri Lanka. Available at http://www.academia.edu/ 17147788/A_Critical_Analysis_of_the_Present _Death_Investigation_System_in_Sri_Lanka 
7. Cooray, LJM. An introduction to the legal system of Ceylon. Colombo: Lake House Investments; 1972

8. Ruwanpura RP, Vidanapathirana M. Historical landmarks of the evolution of forensic medicine and comparative development of medico-legal services in Sri Lanka.

9. Menezes RG, Monteiro FN. Forensic Autopsy.

10. Stevenson R. Death certification practices of forensic physicians within the Strathclyde region of Scotland, UK. Journal of forensic and legal medicine. 2008 May 1;15(4):245-9.

11. Maggs PB, Schwartz O, Burnham W. Law and legal system of the Russian Federation. Juris Publishing, Inc.; 2015.

12. Rognum TO, Vege $\AA$, Stray-Pedersen A, Bøylestad L. A Scandinavian Perspective. InSIDS Sudden Infant and Early Childhood Death: The Past, the Present and the Future 2018 May. University of Adelaide Press.

13. Hanzlick R. The conversion of coroner systems to medical examiner systems in the United States: a lull in the action. The American journal of forensic medicine and pathology. 2007 Dec 1;28(4):279-83.

14. Moore J, editor. Coroners' Recommendations and the Promise of Saved Lives. Edward Elgar Publishing; 2016 Jun 24.

15. Perera C. After the tsunami: Legal implications of mass burials of unidentified victims in Sri Lanka. PLoS Med. 2005 Jun 28;2(6):e185.

16. Fernando LB. Inquests and doctors. Galle Medical Journal. 2009 Sep 28;11(1).

17. Samaranayake R. Inquest procedure: medical officers' point of view. Medico-Legal Journal of Sri Lanka. 2017 Dec 28;5(2).

18. Fernando R. A study of the investigation of death (coroner system) in Sri Lanka. Medicine, science and the law. $2003 \mathrm{Jul}$;43(3):236-40.

19. Kodikara S. Over-a-Century-Old Death Investigation System in Sri Lanka: An Appraisal for Reforms. The American Journal of Forensic Medicine and Pathology. 2013 Sep 1;34(3):2835.

20.Fernando R, Hadisi Marana Parikshana, Colombo, Vijitha Yapa Publications, 2nd Edition, 2002, Page 01

21. Hanzlick R. The conversion of coroner systems to medical examiner systems in the United States: a lull in the action. The American journal of forensic medicine and pathology. 2007 Dec 1;28(4):279-83.

22. Balachandra AT, Vadysinghe AN, William AL. Practice of forensic medicine and pathology in Sri Lanka. Archives of pathology \& laboratory medicine. 2011 Feb;135(2):187-90.

23. Davis JH. The Future of the Medical Examiner System. American Journal of Forensic Medicine and Pathology. 1995 Dec 1;16:265-9.
24. Death investigation: a guide for the death scene investigation. Available at https://www.ncjrs.gov/pdffiles/167568.pdf Date accessed 28 November 2020 